\title{
Analgesic and systemic effects of xylazine, lidocaine and their combination after subarachnoid administration in goats
}

\author{
R DeRossi ${ }^{a^{*}}, A$ L Junqueira ${ }^{a}$ and M P Beretta ${ }^{a}$
}

\begin{abstract}
The objective of the study was to determine the analgesic and systemic effects of subarachnoid administration of xylazine hydrochloride $(X Y)$, lidocaine hydrochloride (LI) and their combination (XYLI) in goats. Six healthy goats were used in a prospective randomised study. Three treatments were administered to each goat, with 1 -week intervals between each treatment. Treatments consisted of $0.1 \mathrm{mg} / \mathrm{kg}$ xylazine, $2.5 \mathrm{mg} / \mathrm{kg}$ lidocaine and a combination of xylazine $0.05(\mathrm{mg} / \mathrm{kg})$ and lidocaine $(1.25 \mathrm{mg} / \mathrm{kg})$. Analgesia, ataxic, sedative, cardiovascular and respiratory effects, and rectal temperature were evaluated before (baseline) and at 5, 10, 15, and $30 \mathrm{~min}$ after subarachnoid injection, and then at 30-min intervals until loss of analgesia occurred. Lidocaine induced analgesia in $3.1 \pm 1 \mathrm{~min}$ (mean $\pm \mathrm{SD}$ ), which lasted for $66 \pm 31 \mathrm{~min}$. Heart and respiratory rates and blood pressure remained unchanged after lidocaine-induced analgesia. Xylazine induced analgesia in $9.5 \pm 2.6 \mathrm{~min}$ and xylazine-lidocaine in $3.2 \pm 1.2 \mathrm{~min}$. Xylazine-lidocaine-induced analgesia lasted longer $(178.3 \pm 37 \mathrm{~min})$ than that induced by xylazine $(88.3 \pm 15 \mathrm{~min})$. The XYLI treatment induced prolonged motor blocking (115 min), more than the XY (80 $\mathrm{min})$ and LI (90 $\mathrm{min}$ ) treatments. Both xylazine and xylazine-lidocaine caused significant decreases in the heart and respiratory rates, but not in blood pressure. The combination of xylazine $(0.05 \mathrm{mg} / \mathrm{kg})$ and lidocaine $(1.25 \mathrm{mg} / \mathrm{kg})$ can be administered subarachnoidally (between last lumbar vertebra and 1st sacral vertebra) to produce prolonged $(>2.5 \mathrm{~h})$ analgesia of the tail, perineum, hind limbs, flanks and caudodorsal rib areas in goats. Despite the prolonged analgesia, using this combination is desirable for relieving postoperative pain, but it may be a disadvantage due to a motor block when dealing with goats.
\end{abstract}

Key words: anaesthesia, goats, lidocaine, subarachnoid, xylazine.

DeRossi R, Junqueira A L, Beretta M P Analgesic and systemic effects of xylazine, lidocaine and their combination after subarachnoid administration in goats. Journal of the South African Veterinary Association (2005) 76(2): 79-84 (En.). Department of Veterinary Medicine-Surgery and Anesthesiology, Faculty of Veterinary Medicine, Federal University of Mato Grosso do Sul State, Brazil.

\section{INTRODUCTION}

Epidural or subarachnoid anaesthesia is considered to be advantageous for general anaesthesia in ruminants ${ }^{25}$. Local anaesthetics have the potential to produce sensory, motor and sympathetic blocking by depressing axonal conduction of nerves. Onset of local anaesthetic effects is characterised by severe motor blocking in the hind limbs. Usually $2 \%$ lidocaine is used with this objective, but higher doses and concentrations induce lesions of the nervous tissues in a temporary or irreversible way $^{18,27}$. The vasodilatation due to sympathetic blocking produced by subarachnoidally-injected local anaesthetics decreases the duration of anaes-

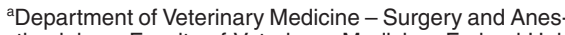
thesiology, Faculty of Veterinary Medicine, Federal University of Mato Grosso do Sul State, Brazil.

*Address for correspondence: Núcleo de Ciências Veterinárias, Universidade Federal de Mato Grosso do Sul, Caixa Postal 549, Campo Grande, CEP 79070-900 MS, Brazil. E-mail: derossi@nin.ufms.br

Received: November 2004. Accepted: May 2005. thesia $^{15,34}$ and induces hypotension ${ }^{30}$.

The use of alpha-2 adrenergic agonists has become popular for epidural or subarachnoid analgesia in goats ${ }^{7,20}$, horses $\mathrm{s}^{22,41}$ and cattle ${ }^{42}$. Subarachnoidally administered xylazine, an alpha-adrenergic agonist most frequently used in veterinary medicine, inhibits spinal substance $P$ release $^{21}$, and nociceptive neuron firing ${ }^{13}$ produced by noxious stimuli and produces analgesia. However, sedation, hypotension, bradycardia, and respiratory depression may occur in goats ${ }^{7,8,20}$.

Previous studies demonstrated that lidocaine or xylazine in combination with other drugs after epidural or subarachnoid administration ${ }^{1,16}$ increased the duration of the analgesic/anaesthetic period. Furthermore, it reduced the doses needed of each drug. All local anaesthetics have a biphasic effect on vascular smooth muscle and at low concentrations tend to cause vasoconstriction $^{19}$. Large doses of epidural xylazine can trigger severe ataxia and deep sedation in horses ${ }^{22}$ and goats ${ }^{8}$. Several studies have shown that local anaesthetics combined with alpha-2 agonist or opioid drugs produce an increase in pain relief duration with epidural administration in humans $\mathrm{s}^{29,32,37}$. The porpose of the present study was therefore to determine whether the combination of low doses of lidocaine and xylazine administered by the subarachnoid route in goats produces analgesia of longer duration with fewer side-effects than subarachnoid lidocaine or xylazine administered alone at doses clinically used in veterinary medicine.

\section{MATERIALS AND METHODS}

Six adult healthy goats ( 1 male and 5 females) ranging from 12 to 26 months in age and from 23 to $40 \mathrm{~kg}$ (mean, $30 \mathrm{~kg}$ ) were selected for the study. The experimental animals were kept at the Veterinary Science Centre, Federal University of Mato Grosso do Sul State, under uniform management conditions and also accustomed to the personnel conducting the experiments. Goats were allowed ad libitum access to food and water until the beginning of each experiment and were also allowed to eat hay during the experiment. The observers were blinded to the drugs and doses administered in each study. Each animal received xylazine hydrochloride (Dorcipec $2 \%$, Vallée Veterinary Products Ltda, São Paulo, Brazil) $(0.1 \mathrm{mg} / \mathrm{kg}), 2 \%$ lidocaine hydrochloride (Lidocaína sem vasoconstritor $2 \%$, Hipolabor Farmacêutica Inc, Sabará, Brazil) $(2.5 \mathrm{mg} / \mathrm{kg})$ or xylazine $(0.05 \mathrm{mg} / \mathrm{kg})$ and $2 \%$ lidocaine $(1.25 \mathrm{mg} / \mathrm{kg})$, in random order at 1-week intervals. The study was approved by the Ethics Committee of Federal University of Mato Grosso do Sul State.

All animals received 3 treatments. The area was aseptically prepared, clipped, and scrubbed with povidine-iodine and infiltrated with lidocaine $1 \%(1 \mathrm{ml})$ at the entry point. The hypodermic needle (20-gauge, $3.5 \mathrm{~cm}$ long) was directed to the spinal cord at a $45^{\circ}$ angle along the median plane. The lumbosacral space was identified by the depression between the 
last lumbar vertebra and the 1 st sacral vertebra and the presence of the needle in the subarachnoid space was confirmed by a free flow of CSF from the needle. Three treatments used were: xylazine, $0.1 \mathrm{mg} / \mathrm{kg}$ (XY; mean dose $3.5 \mathrm{mg}$ ); $2 \%$ lidocaine, $2.5 \mathrm{mg} / \mathrm{kg}$ (LI; mean dose $93 \mathrm{mg}$ ), and xylazine, $0.05 \mathrm{mg} / \mathrm{kg}$ and $2 \%$ lidocaine, $1.25 \mathrm{mg} / \mathrm{kg}$ (XYLI; mean dose $1.75 \mathrm{mg}$ and $45 \mathrm{mg}$ ). The volume of all treatments was adjusted to $1 \mathrm{~m} / 7.5 \mathrm{~kg}$ body weight by the use of saline $(0.9 \%)$ solution (Hidrate ${ }^{\circ}$, Pharmaceutical Products Ltda, Campo Grande, Brazil), when necessary. The drugs were injected in the subarachnoid space of each experimental animal.

Heart rate (HR), respiratory rate (RR), peripheral oxygen saturation $\left(\mathrm{SpO}_{2}\right)$, and arterial blood pressure [systolic (SAP), mean (MAP), and diastolic (DAP)] were recorded before injection (baseline), 5, 10 and 15 min after injection, and at 30-min intervals thereafter until the analgesic effect disappeared. Arterial blood pressures were measured using a non-invasive device (EMAI-RX 300 blood pressure monitor, Transmai Equipamentos Médicos Hospitalares Ltda, São Paulo, Brazil), with the cuff attached to the proximal third of the radius in order to measure the pressure in the brachial artery ${ }^{8,36}$. The peripheral oxygen saturation $\left(\mathrm{SpO}_{2}\right)$ was measured through a sensor(EMAI-RX 300 oxygen monitor, Transmai Equipamentos Médicos Hospitalares Ltda, São Paulo, Brazil) attached to the inguinal pleat, which had been shaved. The heart rate (HR) was measured through an electrocardiograph (EMAI-RX 300 cardiac monitor, Transmai Equipamentos Médicos Hospitalares Ltda, São Paulo, Brazil). Arterial pressure, heart rate and $\mathrm{SpO}_{2}$ were measured using a cardiac monitor (RX-300 ${ }^{\mathrm{A}}$, São Paulo, Brazil). The respiratory rate (RR) was measured by counting the chest movements per minute, and the rectal temperature (RT) was measured with a digital thermometer $\left({ }^{\circ} \mathrm{C}\right)$ (Digital Thermometer, Becton Dickinson Inc., Ottawa, Canada.)

All cardiovascular and respiratory variables were recorded before noxious stimulation to establish non-stimulated values. Effects like salivation and urination frequency were also monitored.

Onset and duration of analgesia was determined with a 22-gauge, 2.5 -cm-long needle to assess superficial (needle used to prick the skin) and deep (needle inserted into the muscles) pain in the tail, perineum, hind limbs, flanks and caudodorsal rib areas. Response to these stimuli was rated according to the following scale: 1 , no analgesia (normal strong reaction to painful stimulus); 2 , mild analgesia (depressed reaction to painful stimulus);

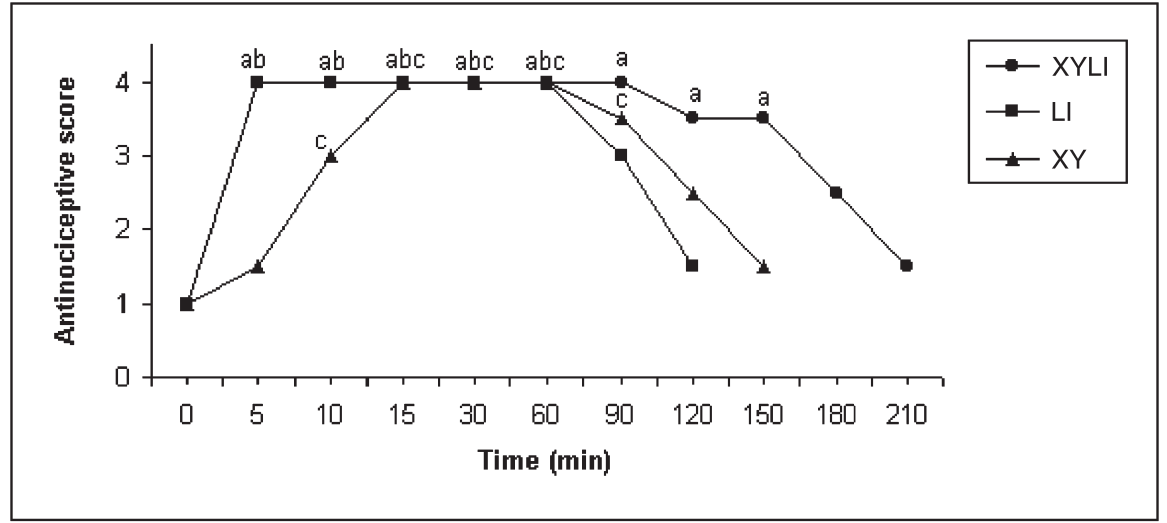

Fig. 1: Median antinociception score in response to a standard noxious stimulus in the tail, perineum, hind limbs, flanks and caudodorsal rib areas after subarachnoid administration of xylazine $(X Y ; 0.1 \mathrm{mg} / \mathrm{kg}$ ), lidocaine $(\mathrm{Ll} ; 2.5 \mathrm{mg} / \mathrm{kg})$ or xylazine/lidocaine $(X Y L I ; 0.05 \mathrm{mg} / \mathrm{kg}$ and $1.25 \mathrm{mg} / \mathrm{kg}$, respectively) in 6 goats. The following scale was used: 1, no analgesia; 2, mild analgesia; 3 , moderate analgesia; and 4 , complete analgesia. ${ }^{a, b, c}$ The value for ${ }^{a} X Y L Y,{ }^{b} \mathrm{LI}$, and ${ }^{c} X Y$ differed significantly $(P<0.05)$ from the respective baseline (time 0 ) value.

3, moderate analgesia (no response to needle-prick stimulation of the skin); and 4, complete analgesia (no response to insertion of the needle deep into the muscle). The degree of sedation was evaluated at each of the recording times after the treatments were given. Grading was performed as follows: 1 , no sedation effect; 2 , mild sedation (reduced alertness without other signs of sedation); 3 , moderate sedation (drowsiness and slight drooping of the head); and 4, severe sedation (severe drowsiness). Ataxic effects were evaluated using the following scale: 1 , no ataxia; 2 , mild ataxia (difficulty in maintaining a standing position); 3 , moderate ataxia (recumbent with movement of hind limbs); and 4, severe ataxia (recumbent without movement of hind limbs). All clinical variables were evaluated immediately before subarachnoid injection (baseline) and at 5, 10, 15, $30 \mathrm{~min}$ following drug administration and thereafter at 30-min intervals. To assess the diffusion extent of all solutions within the subarachnoid space at different intervals, superficial skin pricks and deep needle pricks into the muscle were made at adjacent dermatomic regions, beginning at the tail and proceeding cranially up to the caudodorsal rib area.

Data were analysed using the Statistical Analysis System (SAS 6.12, SAS Institute Inc., Cary, NC, USA). A randomised block design was used for each drug, with time as treatment and each of the 6 animals as a block. For dependent variables HR, SAP, DAP, MAP, RR, $\mathrm{SpO}_{2}$ and RT analysis of variance differed from baseline (time 0 ). For analgesia, ataxia and sedationdependent variables, the non-parametric Friedman test was used, followed by multiple data comparisons. The Dunnett rank test was also applied, with time 0 being considered as baseline. In each analysis, differences were considered significant if $P<0.05$.

\section{RESULTS}

Subarachnoid injection of the drugs at the lumbosacral space was made without any problems in all animals. The analgesia test through a needle-prick was efficient and demonstrated which dermatomes were blocked after subarachnoid administration of the drugs. The onset of analgesia began in the tail and after that spread to other regions, progressing cranially to the flanks. The xylazine-lidocaine combination produced a longer duration of complete analgesia $(178.3 \pm 37$ min, mean $\pm \mathrm{SD})$ than xylazine $(88.3 \pm 15 \mathrm{~min})$ or lidocaine ( $66 \pm 31 \mathrm{~min}$ ) alone in the region of the tail, perineum, hind limbs, flanks and dorsocaudal rib areas in goats. Complete analgesia (grade 4) began in $3.2 \pm 1.2 \mathrm{~min}$ in the XYLI treatment, similar to the LI treatment $(3.1 \pm 1 \mathrm{~min})$, but the onset was delayed with the $X Y$ treatment $(9.5 \pm$ 2.6 min) (Fig. 1). The extent of analgesia obtained with the XYLI treatment was similar to that obtained with the $X Y$ treatment, extending to dermatomic region $\mathrm{T}_{10 \pm 12}$, but with the LI treatment, analgesia extended only up to dermatomic region $\mathrm{L}_{1}$. All animals in the 3 groups showed recumbency. The ataxic effect was more prolonged in the XYLI treatment, lasting 115 min (score 4), while in the XY and LI treatments, it lasted $80 \mathrm{~min}$ and 90 min, respectively (Fig. 2). Subarachnoid administration of the XY or XYLI treatments induced sedation; however, it was more evident and prolonged after the $\mathrm{XY}$ treatment (Fig. 3). Salivation was evident in all goats at all intervals after the $X Y$ treatment, and from 10 to $30 \mathrm{~min}$ in the ataxia and subsequently attained sternal 


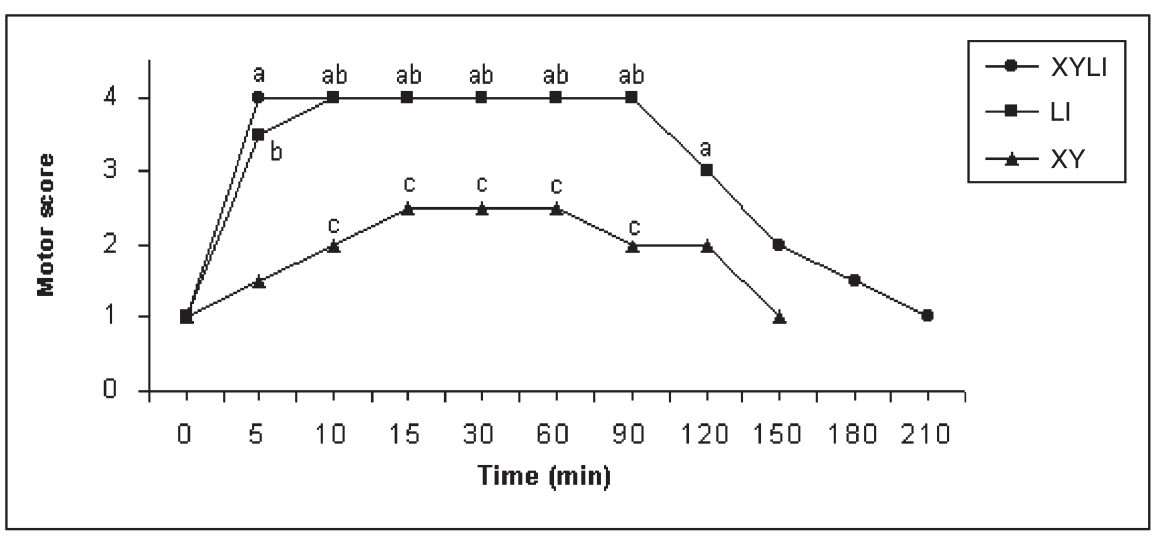

Fig. 2: Median score for the ataxic effects of subarachnoid administration of $\mathrm{XYLI}, \mathrm{LI}$ or $\mathrm{XY}$ to 6 goats. Ataxic scores were as follows: 1 , no ataxia; 2 , mild ataxia; 3 , moderate ataxia; and 4 , severe ataxia. ${ }^{\mathrm{a}, \mathrm{b}, \mathrm{c}}$ The value for ${ }^{\mathrm{a}} \mathrm{XYLY},{ }^{\mathrm{b}} \mathrm{LI}$, and ${ }^{\mathrm{c}} \mathrm{XY}$ differed significantly $(P<0.05)$ from the respective baseline (time 0 ) value.

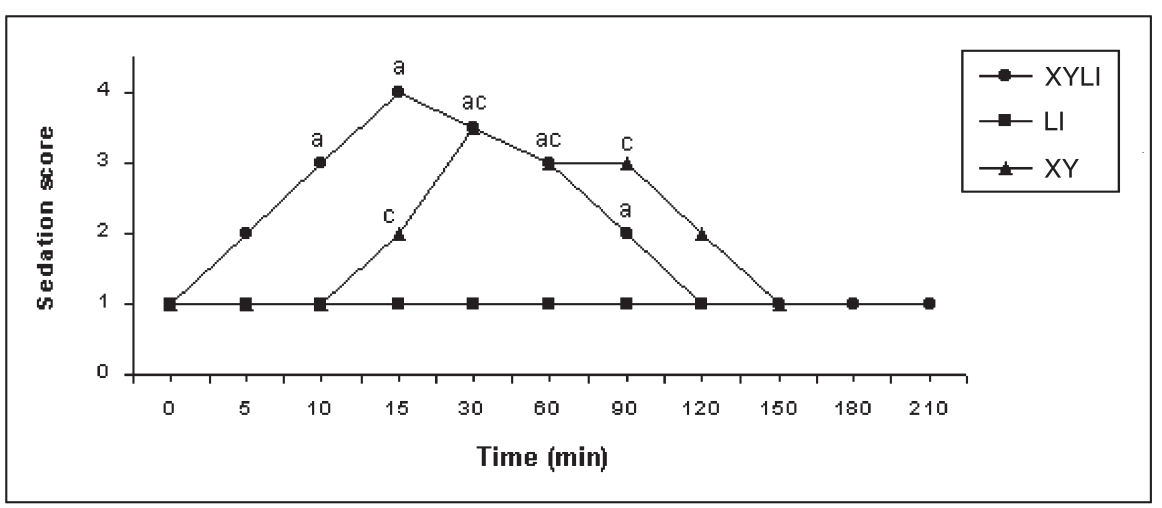

Fig. 3: Median score for sedation in response to subarachnoid administration of XYLI, LI or $X Y$ in 6 goats. Sedation scores were as follows: 1 , no sedation; 2 , mild sedation; 3, moderate sedation; and 4, severe sedation. ${ }^{\mathrm{a}, \mathrm{b}, \mathrm{c}}$ The value for ${ }^{\mathrm{a} X Y L Y,}{ }^{\mathrm{b}} \mathrm{LI}$, and ${ }^{\mathrm{c}} \mathrm{XY}$ differed significantly $(P<0.05)$ from the respective baseline (time 0$)$ value.

XYLI treatment. Also, all goats urinated frequently (mean of 3 times) throughout the experimental period after subarachnoid administration of the XY or XYLI treatments.

Subarachnoid injection of xylazine induced a significant decrease $(P<0.05)$ in HR, compared with the baseline value, from 10 min after injection until the end of the experiment. The XYLI treatment caused significant decreases $(P<0.05)$ in HR from 30 to $90 \mathrm{~min}$. The LI treatment did not cause significant differences $(P<$ $0.05)$ in $\mathrm{HR}$ at any time interval. Arterial pressures (SAP, DAP and MAP) did not change significantly from baseline values following the subarachnoid XY, LI or XYLI treatments (Table 1). Respiratory rate decreased significantly from 10 to 150 min after the $\mathrm{XY}$ treatment and there was also a significant decrease in $\mathrm{SpO}_{2}$ from 10 to $30 \mathrm{~min}$ after the $X Y$ treatment. The XYLI treatment decreased RR significantly $(P<$ $0.05)$ at $15 \mathrm{~min}$, but did not alter peripheral $\mathrm{O}_{2}$ significantly. Four goats given the $\mathrm{XY}$ treatment and 1 goat given the XYLI treatment had irregular and reduced RR 10 min after injection, but all of them returned to baseline values at the end of the experiment. Rectal temperature remained stable after the XYLI treatments, but the subarachnoid $X Y$ or LI treatments induced a significant decrease $(\mathrm{P}<0.05)$ in RT, compared to the baseline value, from 60 to $150 \mathrm{~min}$ and from 5 to $180 \mathrm{~min}$, respectively (Table 2 ).

\section{DISCUSSION}

The results of the study indicated that the subarachnoid administration of xylazine-lidocaine induced analgesia in the regions of the tail, perineum, hind limbs, flank and caudodorsal ribs in goats, and the degree of analgesia was more profound and the duration was greater than that induced by the use of xylazine or lidocaine alone. Adverse effects of subarachnoidally-administered xylazine included sedation, decrease in HR and salivation and frequency of urination. In our experiment, xylazine-lidocaine at a dosage of $0.05 \mathrm{mg} / \mathrm{kg}$ and $1.25 \mathrm{mg} / \mathrm{kg}$, respectively, administered subarachnoidally produced analgesia with a duration twice as long (178.3 $\pm 37 \mathrm{~min})$ as that observed after administration of xylazine $(88.3 \pm 15 \mathrm{~min})$ or lidocaine $(66 \pm 31 \mathrm{~min})$ $R R$, ataxia, recumbency and increase in alone. The onset of the analgesia of the studied regions, which firstly began in the tail and extended to cranial dermatomes was $\pm 3 \mathrm{~min}$ in the XYLI and LI treatments, but the onset in the $X Y$ treatment was more delayed $(9.5 \pm 2.6 \mathrm{~min})$. Analgesia produced by epidural or subarachnoid administration of lidocaine has a faster onset compared to xylazine in goats ${ }^{8}$ and medetomidine in cows ${ }^{24}$. Similar results were obtained in the present study with local anaesthetics such as xylazine producing a delayed response to the onset of analgesia. A delayed onset of analgesia by xylazine compared to lidocaine has been reported in various animals $\mathrm{s}^{2,12,16}$. The duration of analgesia in the studied regions after subarachnoid administration of half-doses of lidocaine in combination with the half-doses of xylazine caused analgesia blocking with a 2 -fold longer duration than that observed with the use of either drug alone at full dose. Compared to local anaesthetics, but similar to opioids, detailed studies have shown that alpha-2 agonists tend to produce variable or patchy segmental effects $^{39,40}$. For this reason, xylazine and the opioids are often combined with other drugs, such as local anaesthetics, for caudal epidural analgesia in horses ${ }^{16,33}$. The effect of subarachnoidally-applied local anaesthetic drugs on spinal blood flow is of interest because disturbances in normal neurological function and neurotoxicity can result from reduced blood flow $^{14,18,38}$. Alpha-2 adrenergic stimulation of vascular smooth muscle by xylazine via activation of post-synaptic alpha-2 adrenoceptors may reduce spinal blood flow, producing spinal ischaemia with neuronal damage. However, in slow doses the spinal blood flow was not influenced by the epidural administration of a preservative-free alpha-2 agonist solution in sheep ${ }^{11}$ or horses ${ }^{23}$.

Agonists of alpha-2 adrenergic receptors produce analgesia by their action on receptors in the substantia gelatinosa of the dorsal horn of the spinal cord. Xylazine may also have a local anaesthetic-like action on spinal nerves ${ }^{3,33}$. All animals given the 3 treatments - XY, LI or XYLI presented incoordination and recumbency, being more delayed in the XYLI treatment, which suggests that xylazine may also have had a local anaesthetic action. It has been speculated that some of the efficacy of alpha-2 adrenergic agonists in producing analgesia following their regional injection may result from their local anaesthetic action on $\mathrm{A}$ and $\mathrm{C}$ fibres ${ }^{5}$. Inhibition of the $\mathrm{A}$ fibres probably leads to motor blocking. In this study, in the combination treatment, the motor blocking achieved was 


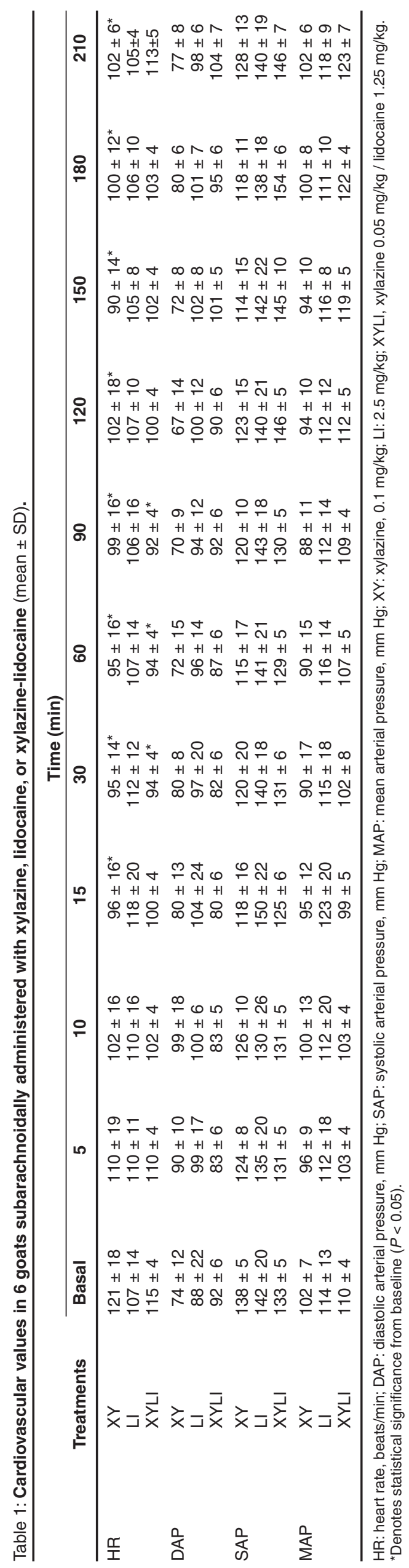

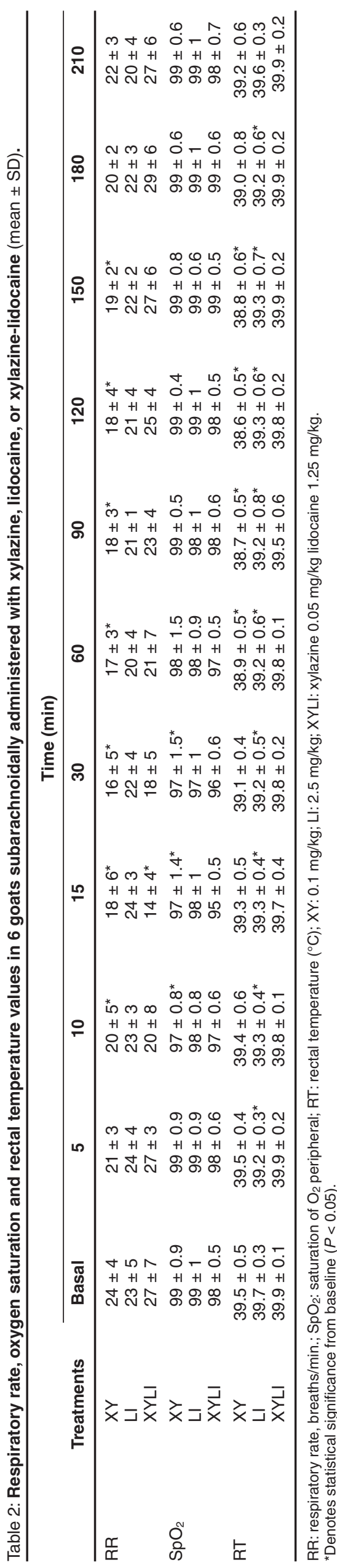

much more than in the other two groups. This could be attributed to different sites of action of both drugs. Stimulation of post-junctional alpha-2 adrenoceptors located in arterial and venous vasculature often produces vasoconstriction $^{28}$. We speculate that the vasoconstriction produced by xylazine allows a prolonged presence of both drugs in the spinal effect. Maximal spread of analgesia in response to pinprick stimulation was up to the 10th thoracic vertebra in both $X Y$ and $X Y L I$ treatments and up to the $L_{1}$ in the LI treatment. Lipophilicity correlated well with the permeability coefficient in a biphasic fashion and, hence, may be the principal determinant of drug flux through the lipid and aqueous tissues of the spinal meninges ${ }^{4}$. This was probably not due to the volume or site of injection, but to the liposolubility characteristics of xylazine $e^{6,7}$.

Systemic effects of subarachnoidally administered xylazine and xylazinelidocaine were evidenced by profound sedation and salivation, similar to those reported after subarachnoid xylazine administration in goats ${ }^{20}$ or cattle $^{42}$, indicating rapid vascular or/and lymphatic absorption from the subarachnoid space. All experimental animals showed an increase in the frequency of urination after subarachnoid administration of xylazine and xylazine-lidocaine. This effect may be associated with the inhibition of antidiuretic hormone release from the pituitary, antagonism of the renal tubular action of antidiuretic hormone, increase in glomerular filtration rate and release of atrial natriuretic factor ${ }^{24}$.

The reduction in rectal temperature observed in goats after administration of xylazine may have been caused by sedation, reduced metabolism, muscle relaxation and depression of the $\mathrm{CNS}^{20}$. In addition, alpha-2 agonists reportedly induce prolonged depression of thermoregulation. A combination of these mechanisms could potentially result in hypothermia ${ }^{31}$. A decrease in rectal temperature after administration of anaesthetics has been reported in other studies on goats $^{2,20}$. In our study, lidocaine induced a long-lasting decrease in rectal temperature, possibly because of regional vasodilatation induced by the anaesthetics.

Cardiovascular effects induced by xylazine are the result of stimulation of peripheral or central alpha-2 adrenoceptors. Stimulation of pre- 
junctional alpha-2 adrenoceptors results in inhibition of release of norepinephrine from peripheral nerve endings, which, in part, contributes to the bradycardiac effect of the drugs. Subarachnoid administration of xylazine and xylazine-lidocaine induced a significant decrease in HR. Heart rate did not show any change after subarachnoid administration of lidocaine. This is similar to the results obtained with epidural xylazine in cattle ${ }^{42}$ and mares $^{39}$, epidural clonidine in sheep ${ }^{10}$ and subarachnoid xylazine and medetomidine in goats ${ }^{20}$. The decrease in HR was less pronounced in the combination treatment. This might be due to the low dose of xylazine used in this group $(0.05 \mathrm{mg} / \mathrm{kg})$. Several mechanisms contribute to the alpha-2 adrenergic agonist-induced bradycardia, which include decreased sympathetic outflow from the central nervous system, inhibition of norepinephrine release from sympathetic nerve terminals, direct depression of cardiac pacemaker and conduction tissue, increased vagal tone and a direct increase in the release of acetylcholine from parasympathetic nerves in the heart ${ }^{26}$. In this study, arterial blood pressure in the goats that received xylazine and xylazinelidocaine did not change significantly from baseline values. In $\operatorname{dog} s^{43}$, MAP had a biphasic (increased then decreased) response, similar to that observed after IV administration of medetomidine, and other alpha-2 adrenergic agonist drug, to rats $^{35}$. This biphasic effect is caused by stimulation of the peripheral alpha-2 adrenergic receptors located in the vascular wall, which is followed by central and peripheral effects resulting in secondary hypotension $^{35}$. Alpha-2 adrenergic agonist drugs have a prevalent peripheral action compared with their central action, this effect being determined by the dose and frequency of administration. Intermediate dose of epidural xylazine, in contrast to small or large ones, causes the largest decrease in blood pressure. The fact that higher doses did not result in a more marked decrease in arterial blood pressure was thought to be a reflection of the peripheral alpha- 2 receptor effects 9 Local anaesthetics, like lidocaine cause an indiscriminate blockage of the sensory, sympathetic and motor fibres. The sympathetic block induces vasodilatation in the anaesthetised areas, producing hypotension in clinical doses. In our study, the doses of lidocaine, xylazine and half-doses used in combination did not produce significant decreases in the arterial pressure compared to the basal value.

Subarachnoid administration of $X Y$ and XYLI caused irregularity and a significant reduction in $R R$, but only the $X Y$ treatment decreased $\mathrm{SpO}_{2}$. Significantly decreased respiratory rate and $\mathrm{PaO}_{2}$ were recorded after xylazine administered epidurally in cattle $^{41}$ or subarachnoidally in goats ${ }^{20}$ and those authors cited literature supporting the idea that the respiratory effects of epidural or subarachnoid administration of xylazine are mediated through alpha-2 adrenoceptors activity ${ }^{2}$.

\section{CONCLUSIONS}

The results of this study indicate that injection of a combination of xylazine and lidocaine in half-doses $(0.05 \mathrm{mg} / \mathrm{kg}$ and $1.25 \mathrm{mg} / \mathrm{kg}$, respectively) into the subarachnoid space induces more prolonged ( $>2.5$ hours) analgesia in the tail, perineum, hind limbs, flanks and caudodorsal rib areas than that observed with the use of either drug alone at the full dose in goats. However, in combination they caused a significant decrease in heart rate and respiratory rate as well as significant ataxia and sedation.

\section{ACKNOWLEDGEMENTS}

This study was supported by the Foundation of Teaching, Science and Technology Development, Mato Grosso do Sul State.

\section{REFERENCES}

1. Aithal H P, Amarpal Pratap K, Kinjavdekar P, Pawde A M, Pratap K 2001 Analgesic and cardiopulmonary effects of intrathecally administered romifidine or romifidine and ketamine in goats (Capra hircus). Journal of the South African Veterinary Association 72: 84-91

2. Aithal H P, Amarpal Pratap K, Singh G R 1996 Clinical effects of epidurally administered ketamine and xylazine in goats. Small Ruminant Research 24: 55-64.

3. Aziz M.A, Martin R J 1978 Alpha agonist and local anaesthetic properties of xylazine. Zentralblatt für Veterinärmedizin (A) 25: 181-188

4. Bernards C M, Hill H F 1992 Physical and chemical properties of drug molecules governing their diffusion through the spinal meninges. Anesthesiology 77: 750-756

5. Butterworth J F, Strichartz G R 1993 The alpha-2 adrenergic agonists clonidine and guanfacine produce tonic and phastic block of conduction in rat sciatic nerve fibres. Anesthesia \& Analgesia 76: 295-30

6. Caron J P, LeBlanc P H 1989 Caudal epidural analgesia in cattle using xylazine. Canadian Journal of Veterinary Research 53: 486-489.

7. DeRossi R, Gaspar E B, Junqueira A L, Beretta M P 2003 A comparison of two subarachnoid $\alpha_{2}$-agonists, xylazine and clonidine, with respect to duration of antinociception and hemodynamic effects in goats. Small Ruminant Research 47: 103111

8. DeRossi R, Junqueira A L, Beretta M P 2003 Analgesic and systemic effects of ketamine, xylazine and lidocaine after subarachnoid administration in goats. American Journal of Veterinary Research 64: 51-56

9. Eisenach J C, Detweller D, Hood D 1993 Hemodynamic and analgesic actions of epidurally administered clonidine. Anesthe- siology 78: 277-287

10. Eisenach J C, Dewan D M, Rose J C, Angelo J M 1987 Epidural clonidine produces antinociception, but not hypotension, in sheep. Anesthesiology 66: 496-501

11. Eisenach J C, Grice S C 1988 Epidural clonidine does not decrease blood pressure or spinal cord blood flow in awake sheep. Anesthesiology 68: 335-340

12. Fike I W, Lin H C, Thurmon J C 1989 A preliminary comparison of lidocaine and xylazine as epidural analgesics in ponies. Veterinary Surgery 18: 85-86

13. Fleetwood-Walker S M, Mitchell R, Hope P J, Molony V, Zygo A 1985 An alpha-2 receptor mediates the selective inhibition by noradrenaline of nociceptive responses of identified dorsal horn neurons. Brain Research 334: 243-254

14. Freedman J, Post C, Kahrstrom J, Ohlen A, Mollenhott P, Owman C, Alari L, Hokfelt T 1988 Vasoconstrictor effects in spinal cord of substance P antagonist [D-Arg, D-Trp7,9, Leu11]-substance P (spantide) and somatostatin and interaction with thyrotropin releasing hormone. Neuroscience 27: 267-278

15. Gómez de Segura I A, Vazquez I, DeMiguel E 2000 Antinociceptive and motor-blocking action of epidurally administered IQB-9302 and bupivacaine in the dog. Regional Anesthesia and Pain Medicine 25: 522-528

16. Grubb T L, Reibold T W, Huber M J 1993 Evaluation of lidocaine, xylazine and a combination of lidocaine and xylazine for epidural analgesia in llamas. Journal of the American Veterinary Medical Association 203: 1441-1444

17. Grubb T L, Riebold T W, Huber M J 1992 Comparison of lidocaine, xylazine and xylazine/lidocaine for caudal epidural analgesia in horses. Journal of the American Veterinary Medical Association 201: 1187-1190

18. Hodgson P S, Neal J M, Pollock J E, Liu S S 1999 The neurotoxicity of drugs given intrathecally (spinal). Anesthesia E Analgesia 88: 797-809

19. Johns R A, Seyde W C, DiFazio C A, Longnecker D E 1986 Dose-dependent effects of bupivacaine on rat muscle arterioles. Anesthesiology 65: 186-191

20. Kinjavdekar P, Singh Amarpal G R, Aithal H P, Pawde AM 2000 Physiology and biochemical effects of subarachnoidally administered xylazine and medetomidine in goats. Small Ruminant Research 38: 217-228

21. Kuraishi Y, Hirota N, Sato Y, Kaneko S, Satoh M, Takagi H 1985 Noradrenergic inhibition of the release of substance P from the primary afferent in the rabbit spinal dorsal horn. Brain Research 359: 177-182

22. LeBlanc P H, Caron J P, Patterson J S, Brown M, Matta M A 1988 Epidural injection of xylazine for perineal analgesia in horses. Journal of the American Veterinary Medical Association 193: 1405-1408

23. LeBlanc P H, Caron J P 1990 Clinical use of epidural xylazine in the horse. Equine Veterinary Journal 22: 180-181

24. Lin H C, Trachte E A, DeGraves F J, Rodgerson D H, Steiss J E, Carson R L 1998 Evaluation of analgesia induced by epidural administration of medetomidine to cows. American Journal of Veterinary Research 59: 162-167

25. Lumb W V, Jones E W 1984. Spinal anesthesia. In Veterinary anesthesia (2nd edn). Lea \& Febiger, Philadelphia: 408-413

26. MacDonald E, Virtanen R 1992. Review of 
the pharmacology of medetomidine and detomidine: two chemically similar $\alpha-2$ adrenoceptor agonists used as veterinary sedative. In Short C E, Poznak A V (eds) Animal pain. Churchill Livingstone, New York: 181-191

27. Malinovsky J M, Pinaud M 1996 Neurotoxicité des agents administrés par voie intrathécale. Annales Françaises d'Anesthésie et de Réanimation 15: 647-658

28. Maze M, Tranquilli W 1991 Alpha-2 adrenoceptor agonists: defining the role in clinical anesthesia. Anesthesiology 74: 581-605

29. Milligan K R, Convery P N, Weir P, Quinn P, Connoly D 2000 The efficacy and safety of epidural infusions of levobupivacaine with and without clonidine for postoperative pain relief in patients undergoing total hip replacement. Anesthesia \& Analgesia 91: 393-397

30. Nolte I, Watney G C G, Hall L W 1983 Cardiovascular effects of epidural blocks in dogs. Journal of the Small Animal Practice 24: 17-21

31. Ponder S W, Clarke W G 1980 Prolonged depression of thermoregulation after xylazine administration in cats. Journal of Veterinary Pharmacology and Therapeutics 3: 203 207

32. Purdie N L, McGrady E M 2004 Comparison of patient-controlled epidural bolus admin- istration of ropivacaine and $0.1 \%$ levobupivacaine, both with $0.0002 \%$ fentanil from analgesia during labour. Anaesthesia 59: 133-137

33. Robinson E P, Natalini C C 2002 Epidural anesthesia and analgesia in horses. Veterinary Clinics of North America: Equine Practice 18: $61-82$

34. Sakura S, Sumi M, Yamada Y, Saito Y, Kosaka Y 1998 Quantitative and selective assessment of sensory block during lumbar epidural anaesthesia with $1 \%$ or $2 \%$ lidocaine. British Journal of Anaesthesia 81: 718-722

35. Savola J M 1989 Cardiovascular actions of medetomidine and its reversal by atipamezole. Acta Veterinaria Scandinavia 85: 39-47

36. Sawyer D C, Brown M, Striler E L, Durham M A, Langham M A, Rech R H 1991 Comparison of direct and indirect blood pressure measurement in anesthetised dogs. Laboratory Animal Science 41: 134-138 37. Senard M, Kaba A, Jacquemin M J, Maquoi L M, Geortay M P, Honore Lamy M L, Joris J L 2004 Epidural levobupivacaine $0.1 \%$ or ropivacaine $0.1 \%$ combined with morphine provides comparable analgesia after abdominal surgery. Anesthesia $\mathcal{E}$ Analgesia 8: 389-394

38. Skarda R T, Muir W W 2003 Analgesic, behavioral, and hemodynamic and respira- tory effects of midsacral subarachnoidally administered ropivacaine hydrochloride in mares. Veterinary Anaesthesia and Analgesia 30: $37-50$

39. Skarda R T, Muir W W 1996 Analgesic, hemodynamic, and respiratory effects of caudal epidurally administered xylazine hydrochloride solution in mares. American Journal of Veterinary Research 57: 193-200

40. Skarda R T, Muir W W 1994 Caudal analgesia induced by epidural or subarachnoid administration of detomidine hydrochloride solution in mares. American Journal of Veterinary Research 55: 670-680

41. Skarda R T, Muir W W 1992 Physiologic responses after caudal epidural administration of detomidine in horses and xylazine in cattle. In Short C E, Poznak A V (eds) Animal pain. Churchill Livingstone, New York: 292-315

42. St Jean G, Skarda R T, Muir W W, Hoffsis G F 1990 Caudal epidural analgesia induced by xylazine administration in cows. American Journal of Veterinary Research 51: 1232-1236

43. Vesal N, Cribb P H, Frketic M 1996 Postoperative analgesic and cardiopulmonary effects in dogs of oxymorphone administered epidurally and intramuscularly, and medetomidine administered epidurally: a comparative clinical study. Veterinary Surgery 25: 361-369 